\title{
Pitfalls of Echocardiography Diagnosis of Anomalous Origin of Left Coronary Artery from the Main Pulmonary Artery
}

\author{
Karen Schultz, MD, Brojendra Agarwala, MD, FACC* \\ Department of Pediatrics, University of Chicago Comer Children's Hospital, Chicago, Illinois, USA
}

\begin{abstract}
A 14-year-old female was referred by her pediatrician for evaluation of chest pain. Most of her chest pain was experienced during school gym class, limiting her participation. No history of syncope was found. She had never been to the emergency room with chest pain. She has always been in good health. Physical examination was normal. A 2D echocardiogram was misleading; however, a color flow Doppler echocardiogram confirmed the diagnosis of anomalous origin of the coronary artery from the main pulmonary artery (ALCAPA). She underwent successful surgical correction with excellent results.

Copyright $\odot 2016$ Science International Corp.
\end{abstract}

\section{Key Words}

Anomalous origin of left coronary artery - Chest pain • 2D-color Doppler echocardiogram

\section{Introduction}

Chest pain in children is a very common presentation in a busy pediatric cardiology practice as well as in the emergency room. The importance of taking a thorough history with respect to exertional chest pain in children cannot be overemphasized. Our purpose is to present a 14-year-old healthy female who presented in our clinic with a history of recurrent chest pain after physical activities. A 2D echocardiogram was misleading, as if the left coronary artery (LCA) arose from the left coronary sinus; however, color Doppler flow

ax +1 2037853346

E-Mail: jshd@scienceinternational.org

http://structuralheartdisease.org/ (c) 2016 Journal of Structural Heart Disease Published by Science International Corp. ISSN 2326-4004

Accessible online at: http://structuralheartdisease.org/ reversal within the LCA confirmed the diagnosis of anomalous origin of the coronary artery from the main pulmonary artery (ALCAPA). Our purpose is to emphasize the importance of color Doppler flow patterns within the coronary arteries to confirm their origins. A 2D echocardiogram alone could be misleading.

The incidence of ALCAPA is 1 in 300,000 live births [1]. Infants usually present with severe congestive heart failure at around 2 months of age when the pulmonary artery pressure decreases. Abdominal colic with feeding that mimics angina pectoris from poor myocardial perfusion can be an earlier presentation.

Our experience strongly emphasizes that only imaging the origin of the LCA from the left coronary sinus by a 2D echocardiogram alone is not enough to exclude this diagnosis [2]. Our patient exemplifies the importance of color flow Doppler imaging to confirm the diagnosis of ALCAPA.

\section{Case Report}

A 14-year-old Hispanic female complained of exertional, nonradiating recurrent chest pain over the left precordium. She described the chest pain as "pinching" in nature and used to get relief with rest. Chest pain had limited her school gym class physical activities. She denied any associated symptoms such as pre-syncope, syncope, or palpitations. She had never been to the emergency room for her chest pain.

${ }^{*}$ Corresponding Author:

Brojendra Agarwala, MD, FACC

University of Chicago Hospitals MC 4051

Pediatric Cardiology

5841 South Maryland Avenue, Chicago, IL 60637, USA

Tel.: +1 773702 6172; Fax: +1 773702 2319; E-Mail: bagarwal@peds.bsd.uchicago. 


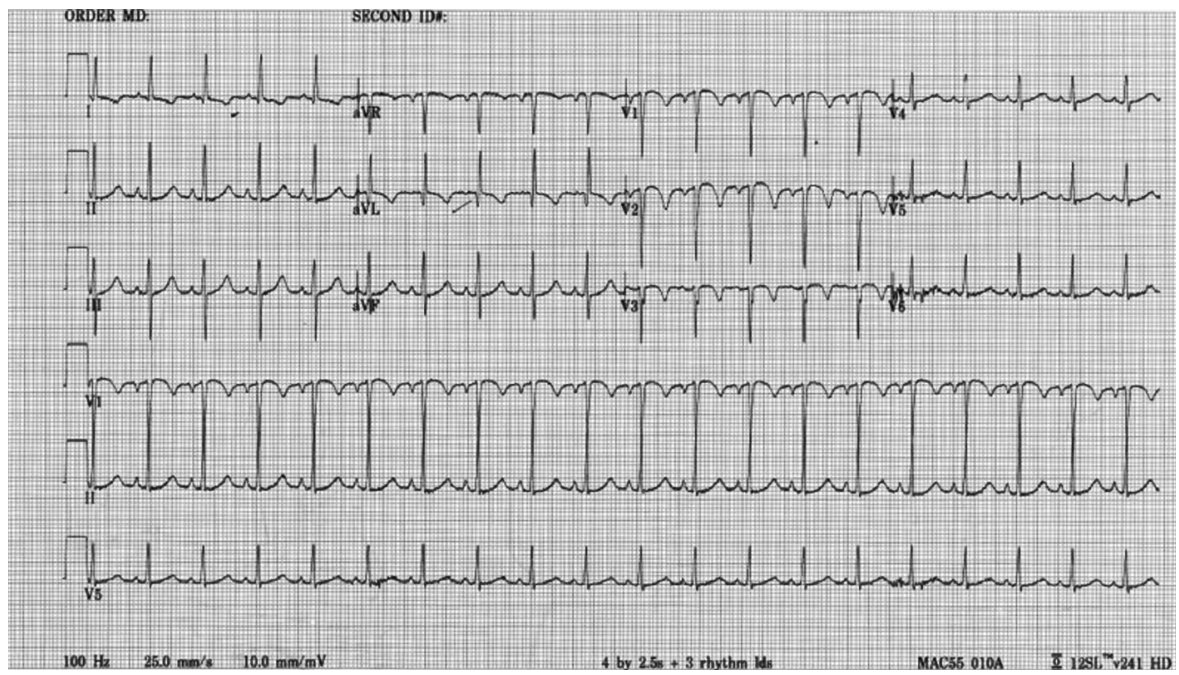

Figure 1. Twelve-lead electrocardiogram showing inverted T in lead I and avL.

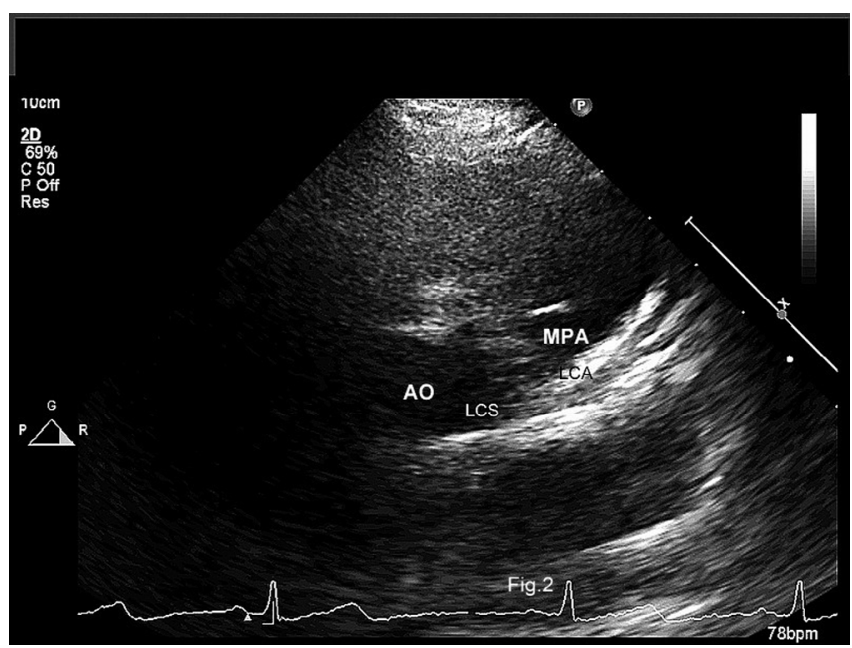

Figure 2. A $2 D$ echocardiogram. The $L C A$ appears to arise from the LCS. AO = aorta; LCA = left coronary artery; LCS = left coronary sinus; MPA = main pulmonary artery.

Her physical examination was unremarkable. Vital signs were heart rate $71 / \mathrm{min}$, respiratory rate $18 / \mathrm{min}$, and blood pressure 110/56 mm Hg. Peripheral pulses were normal and equal in the upper and lower extremities. Cardiac examination revealed normal first and second heart sounds. There was no audible murmur, pericardial rub, or click.

An electrocardiogram (Figure 1) showed normal sinus rhythm and no evidence of chamber hypertrophy. Inverted T in lead I and AVL suggested LV strain. Significant $\mathrm{q}$ in $\mathrm{QVL}$ was also seen. No ST segment changes were seen.

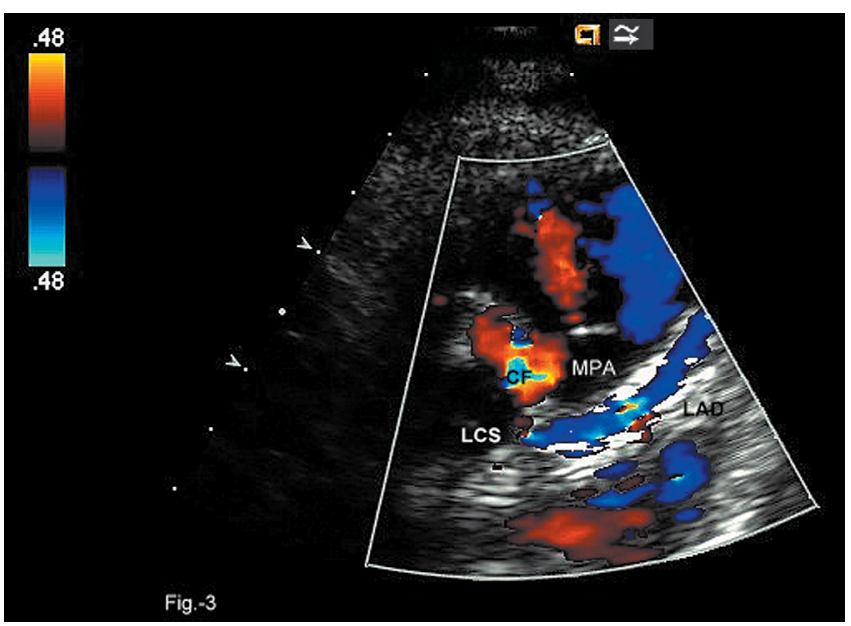

Figure 3. Color flow Doppler mapping showing reversal of color flow within the LCA (blue color). CF =coronary flow; LCA = left coronary artery; LCS = left coronary sinus; MPA = main pulmonary artery.

2D imaging was misleading, as if the LCA arose from the left coronary sinus (Figure 2). However, color Doppler showed reversal of color flow within the LCA (Figure 3) from retrograde filling from the dilated right coronary artery, measuring 4.5 $\mathrm{mm}$ with a z-score of +3.14 (Figure 4 ) by the collateral vessels, suggesting a diagnosis of ALCAPA. This prompted us to explore further with angiography, confirming our diagnosis of ALCAPA (Figures 5 and 6). Subsequently, she underwent corrective surgery with LCA implantation into the aorta with excellent results. 


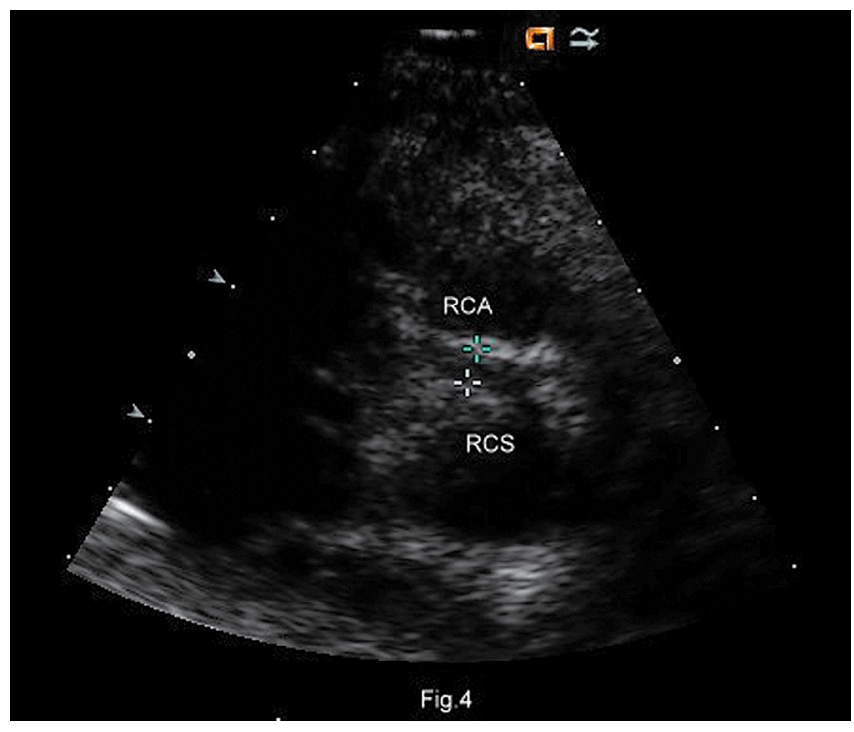

Figure 4. Dilated RCA is arising normally from the RCS. $\mathrm{RCA}=$ right coronary artery; $\mathrm{RCS}=$ right coronary sinus.

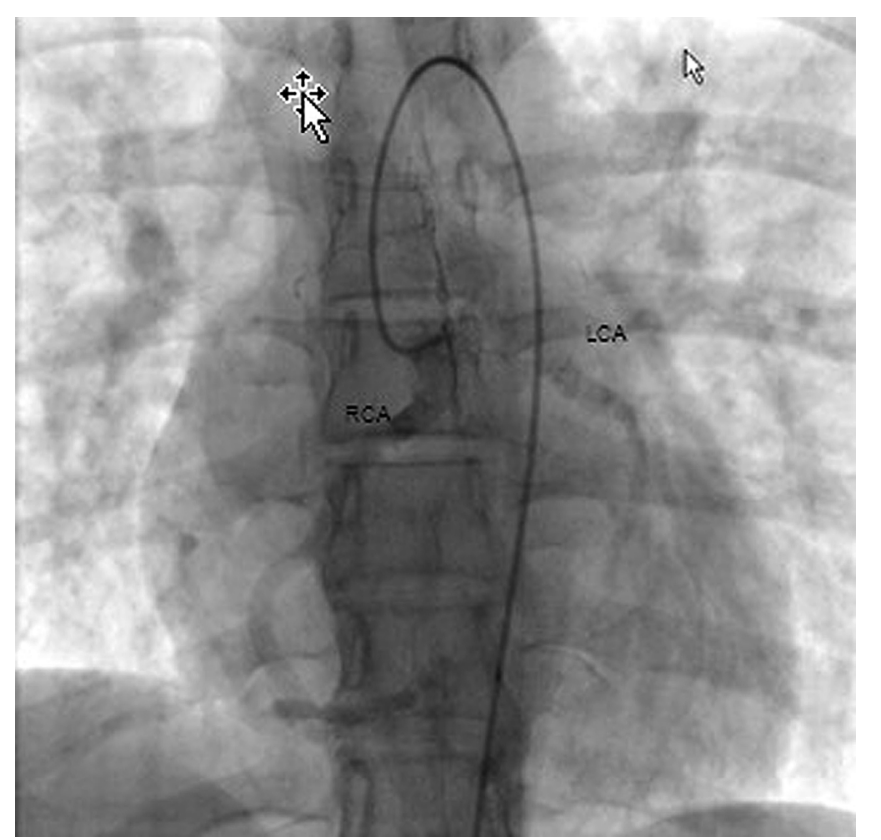

Figure 5. RCA angiogram in the P-A view, showing retrograde filling of the LCA by collaterals. LCA = left coronary artery; RCA = right coronary artery.

\section{References}

1. Aykan AÇ, Yıldız M, Kahveci G, Özkan M. Two adult cases of anomalous left coronary artery from the pulmonary artery. Turk Kardiyol Derm Ars - Arch Turk Soc Cardiol 2012;40: 48-51. DOI: 10.5543/tkda.2012.01605.

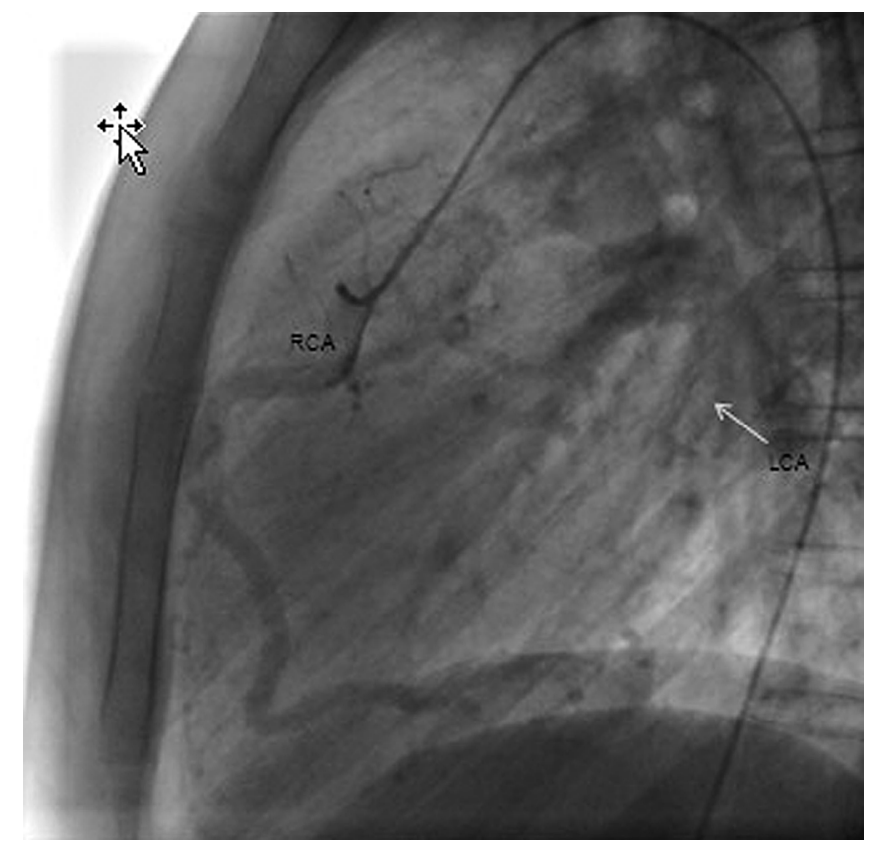

Figure 6. RCA angiogram in the lateral view, showing retrograde filling of the LCA by collaterals (arrow). LCA = left coronary artery; $\mathrm{RCA}=$ right coronary artery.

\section{Conflict of Interest}

The authors have no conflicts of interest relevant to this publication.

\section{Comment on this Article or Ask a Question}

2. Kaku S, Pinto $F$, Magalhães $M$, Fragata J, Ramos JM, Nunes MA, et al. Abnormal origin of left coronary artery from pulmonary artery. Rev Port Cardiol 1995;14:411-418, 361. PMID: 7654402.
Cite this article as: Schultz K, Agarwala B. Pitfalls of Echocardiography Diagnosis of Anomalous Origin of Left Coronary Artery from the Main Pulmonary Artery. Structural Heart Disease 2016;2(2): 58-60. DOI: http://dx.doi.org/10.12945/j. jshd.2016.001.14 